\title{
Book Review: Judiciary-Friendly Forensics of Software Copyright Infringement (Vinod Polpaya Bhattathiripad)
}

Pedro L. P. Sanchez

University of Sao Paulo

Follow this and additional works at: https://commons.erau.edu/jdfsl

Part of the Computer Engineering Commons, Computer Law Commons, Electrical and Computer Engineering Commons, Forensic Science and Technology Commons, and the Information Security Commons

\section{Recommended Citation}

Sanchez, Pedro L. P. (2014) "Book Review: Judiciary-Friendly Forensics of Software Copyright Infringement (Vinod Polpaya Bhattathiripad)," Journal of Digital Forensics, Security and Law. Vol. 9 : No. 4 , Article 5.

DOI: https://doi.org/10.15394/jdfsl.2014.1193

Available at: https://commons.erau.edu/jdfsl/vol9/iss4/5

This Article is brought to you for free and open access by

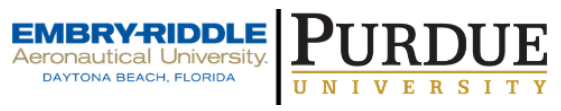
the Journals at Scholarly Commons. It has been accepted for inclusion in Journal of Digital Forensics, Security and Law by an authorized administrator of Scholarly Commons. For more information, please contact commons@erau.edu.

(c)ADFSL 


\title{
BOOK REVIEWS
}

\author{
Diane Barrett \\ Book Review Editor \\ University of Advancing Technology \\ 2625 W. Baseline Rd \\ Tempe, AZ 85283
}

If you have any suggestions on books for review, would like to write a book review for us, or have any comments or concerns on the book reviews published in this column, please feel free to send an email to Diane Barrett, the editor for this column, at book.reviews@jdfsl.org.

\section{Book Review}

Bhattathiripad, Vinod Polpaya. (2014). Judiciary-Friendly Forensics of Software Copyright Infringement. Hershey, PA: IGI Global, 273 pages. ISBN: 978-1466658042. Print/e-book: US \$195.90. Each chapter: US $\$ 37.50$.

Reviewed by Pedro Luís Próspero Sanchez, University of Sao Paulo

Judiciary-Friendly Forensics of Software Copyright Infringement is a book by Dr. Vinod Polpaya Bhattathiripad, published by IGI-Global as part of its Research Essentials series. The book discusses the forensics of software copyright infringement and highlights theoretical, functional, and procedural matters in the investigation of copyright infringement of software products, as well as the development of forensic technologies to detect and avoid software piracy. It is of interest to software forensic experts, lawyers in the field of copyright infringement, judges, software professionals, and students.

Dr. Vinod Polpaya Bhattathiripad has been a cyber-forensic consultant in India in cases related to cyber abuses and specifically on cases related to software copyright infringement. He has extensive experience as a software engineer in about one hundred and fifty projects. He has published internationally on software piracy and copyright infringement forensics. $\mathrm{He}$ is a reviewer of several journals and conference proceedings on digital crime and forensics and has been a technical committee member of several digital crime and forensics conferences in Asia, Europe and the USA. He is the developer of POSAR, a protocol for the forensics of software copyright infringement.

The book covers the combination of two subjects, copyright law and forensics, each one complex and difficult by itself. The book has a list price of US $\$ 195.00$ in hardcover or ebook; discounts may be available directly from the publisher site. Chapters can be bought separately in PDF format through the publisher site, at the somewhat high price of US $\$ 37.50$ each.

Law varies from place to place. It would be impractical to have a single, reasonably sized book covering both copyright law and forensic techniques that would be applicable everywhere. This book focuses mainly on US law, with mentions to the law of some former British Empire countries and the European Union. The book falls very short behind regarding law aspects applicable to digital forensics procedures everywhere else in the world. Essentially, the book is oriented to law 
systems of the common law tradition, but with due care can still be used elsewhere.

The book does not approach any of the several published standards regarding digital forensic techniques and procedures. That is a major shortcoming that should be fixed in future editions of the book.

Chapter 3 introduces and explains various formal software elements and their forensic utility and importance. Various metrics and measures based on these elements are explained as a means for software authorship identification in the context of software copyright infringement forensics. These elements are differentiated based on their relative importance, their subjective nature, and their increased dependability on the investigator's skill, in a way conducive to the assessment of the forensic feasibility and reliability of these elements as means to ascertain software copyright infringement.

Chapter 4 focuses on recommendations, suggestions, and directives from the legal systems on matters related to investigation of software copyright infringement. Samples are taken from various legal systems in order to discuss the ways in which these laws, recommendations, and directives can add credibility to the entire forensic procedure as well as value to the final forensic answers. This analysis is obviously not exhaustive of possibilities, due to the immense variety of law systems at their detail level, but the book shows how to deal with the problem in any particular case well. The chapter makes a good point of stressing the importance of the education on digital forensics of all persons involved, especially judicial officers, so as to make possible intelligent judicial decisions or recommendations on software copyright infringement cases.

Chapter 5 presents an overview of authorship analysis and then explains how authorship analysis can be of help in software copyright infringement forensics. The chapter shows some ways to establish software authorship, using concepts already discussed in chapters 3 and 4 . It concludes by pointing out the limitations and the limited uses of various authorship analysis approaches in the investigation of software copyright infringement.

Chapter 7 discusses the importance of new features which need to be included in any forensic procedures in software copyright infringement cases. It is argued that the incorporation of these new features will result in forensic reports that are more reliable and convincing to the judiciary.

Perhaps one of the most important points in the book is on the possibilities of error in forensic results. Another point is the importance of education on digital forensics for all persons involved in the forensic investigation and the use of its results.

All in all, the book is good guide for a first reading on copyright infringement forensics. It is very useful because it brings to attention every single aspect of the subject. Nevertheless, the book should not be used as the only guide for litigation or forensic procedures in this field because it does not go deep in details and does not cover the important details that depend on each specific jurisdiction. This is not a fault of the book; it is just that the subject is too broad to be dealt with in a single book. 